\title{
PEMBUATAN APLIKASI "AWAS BANG" UNTUK MENINGKATKAN EFISIENSI KEPENGAWASAN PADA SEKOLAH BINAAN DI KABUPATEN BANGKALAN
}

\author{
Yustinus Budi Setyanta \\ Pengawas Cabang Dinas Pendidikan Wilayah Kabupaten Bangkalan Jawa Timur \\ email: yusbuset11@gmail.com
}

(Dikirim: 28 Agustus 2020; Diterima: 30 Desember 2020; Publikasi: 31 Desember 2020)

\begin{abstract}
ABSTRAK
Penelitian yang didesain sebagai penelitian dan pengembangan ini bertujuan mendeskripsikan proses, hasil, dan respons pengawas terhadap pembuatan aplikasi AWAS BANG untuk meningkatkan efisiensi kepengawasan pada sekolah binaan di Cabang Dinas Pendidikan Kabupaten Bangkalan. Pengumpulan data dilakukan melalui studi pustaka, angket, dan wawancara. Melalui tahapan pengumpulan informasi, perancangan, pembuatan aplikasi, uji coba, dan revisi dihasilkan sebuah aplikasi kepengawasan berbasis VBA Macro Excel yang dinamai AWAS BANG (Aplikasi Pengawas Bangkalan). Dampak dari penggunaan aplikasi tersebut berupa efisiensi kepengawasan. Hal itu terindikasikan dari respons pengawas melalui angket. Dari hasil angket diketahui bahwa semua pengawas sekolah di Cabang Dinas Pendidikan Kabupaten Bangkalan merasa terbantu karena tugas kepengawasan menjadi lebih efisien. Selain itu, komunikasi antara pengawas dan sekolah binaan juga menjadi lebih mudah. Para pengawas berharap dilakukan pengembangan aplikasi pada aspek supervisi lain. Dengan demikian, dapat disimpulkan bahwa AWAS BANG dapat meningkatkan efisiensi kepengawasan pada sekolah binaan di Cabang Dinas Pendidikan Kabupaten Bangkalan. Untuk itu disarankan agar aplikasi ini juga digunakan pengawas di daerah lain. Disarankan pula untuk melakukan pengembangan aplikasi ini agar semakin baik dan sempurna.
\end{abstract}

Kata Kunci: aplikasi; efisiensi; kepengawasan

\begin{abstract}
This research, which is designed as research and development, aims to describe the process, results, and responses of supervisors to the AWAS BANG application development to increase the efficiency of supervision in the target schools in the Bangkalan District Education Office Branch. Data collection was carried out through literature study, questionnaires, and interviews. Through the stages of gathering information, designing, making applications, testing, and revising, a VBA Macro Excel-based surveillance application is produced called AWAS BANG (Aplikasi Pengawas Bangkalan). The impact of using these applications is in the form of surveillance efficiency. This was indicated by the supervisor's response through a questionnaire. From the results of the questionnaire, it was found that all school supervisors in the Bangkalan District Education Office Branch felt that their supervisory duties became
\end{abstract}


more efficient. In addition, communication between supervisors and the target schools is also easier. The supervisors hope that application development will be carried out in other aspects of supervision. Thus it can be concluded that the AWAS BANG can improve the efficiency of supervision in the target schools in the Bangkalan District Education Office Branch. For this reason, it is recommended that this application be used by supervisors in other areas. It is also recommended to develop this application to make it better and perfect.

Keywords: application; efficiency; supervision

\section{PENDAHULUAN}

Pengawas sekolah berperan penting dalam peningkatan kualitas pendidikan. Hal itu tidak dapat dimungkiri karena pengawas sekolah memiliki tanggung jawab membangun kerja sama di antara stakeholder sekolah, baik kepala sekolah, guru, maupun tenaga kependidikan. Hal itu perlu dilakukan agar tercipta keselarasan di antara semua komponen sehingga mampu bergerak secara efisien dan efektif sesuai bidang tugas mereka.

Sayangnya, sepanjang pengetahuan penulis ketika masih menjadi guru, kehadiran pengawas ke sekolah binaan seakan-akan hanya sekadar formalitas supervisi. Datang dengan membawa berlembar-lembar kertas untuk diisi oleh sekolah. Satu atau dua minggu kemudian pengawas datang kembali ke sekolah untuk mengambil berkas sesuai tagihan supervisi yang telah diberikan sebelumnya. Hal yang demikian sah-sah saja dilakukan pengawas, terutama yang akses menuju sekolah binaan mudah dikunjungi atau dapat ditempuh dalam kurun waktu yang tidak terlalu lama. Akan tetapi, kondisi sekolah di Indonesia tidak semuanya memiliki akses seperti itu, termasuk di wilayah binaan penulis, Bangkalan Jawa Timur. Ada sekolah yang letaknya jauh di pelosok pedesaan atau di lereng perbukitan yang akses jalannya banyak yang rusak dan berliku-liku serta harus keluar masuk perkampungan atau hutan. Bahkan ada rekan sejawat penulis jika akan melakukan pembinaan (supervisi) terpaksa harus menitipkan kendaraan di rumah penduduk atau di warung pinggir jalan raya. Pengawas tersebut menunggu utusan dari pihak sekolah yang menjemputnya karena akses menuju sekolah binaan tersebut sangat sulit dilalui kendaraan. Akibatnya sudah bisa ditebak. Efisiensi supervisi menjadi terhambat. Akibatnya, pengawas tidak mampu secara optimal membantu pengembangan kualitas pendidikan di sekolah tersebut. 
Yustinus Budi Setyanta

Pembuatan Aplikasi “Awas Bang” untuk Meningkatkan Efisiensi Kepengawasan pada Sekolah Binaan di Kabupaten Bangkalan

Kondisi geografis yang demikian semakin diperparah dengan adanya pandemi covid19 yang sudah berbulan-bulan belum menunjukkan penurunan secara signifikan. Hal itu tentu saja membawa dampak luar biasa bagi seluruh bidang kehidupan, termasuk dalam dunia pendidikan. Sejak April hingga September, dapat dikatakan aktivitas pembelajaran tatap muka di sekolah berhenti. Peserta didik belajar di rumah dan guru juga mengajar dari rumah secara daring. Pengawas pun terkena imbasnya karena supervisi tidak dapat dilakukan secara intensif.

Melihat kenyataan yang demikian, perlu dicari solusi agar pengawas sekolah tetap mampu melaksanakan program kerja yang sudah disusun. Untuk itu, diperlukan adanya suatu inovasi agar pembinaan tetap dapat dijalankan, di mana pun dan dalam kondisi apa pun, sekolah yang dibinanya dapat berkembang secara optimal melalui pembinaan pengawas. Salah satu cara yang dilakukan penulis selaku pengawas sekolah adalah dengan menciptakan aplikasi kepengawasan yang berbasis VBA (Visual Basic for Application) yang notabene merupakan microsoft excel. Hal itu merupakan salah satu kompetensi yang harus dimiliki pengawas sekolah, yakni berkaitan dengan penelitian dan pengembangan.

Aplikasi tersebut penulis namai AWAS BANG, singkatan dari Aplikasi Pengawas Bangkalan. Instrumen yang ada dalam aplikasi tersebut disesuaikan dengan Program Kerja Kepengawasan, baik Program Tahunan maupun Program Semester. Sebagai contoh, pada Juli dilakukan supervisi yang berkaitan dengan kegiatan awal tahun, seperti PPDB, MPLS, dan Administrasi Kurikulum. Pada Agustus dilaksanakan supervisi Kelembagaan, Ketenagaan, dan Pembiayaan. Pada September dilaksanakan supervisi Sarana dan Prasarana. Begitu pula pada bulan-bulan berikutnya. Di samping itu, perlu juga dibuat beberapa aplikasi lain, misalnya verifikasi/validasi KTSP dan supervisi yang berkaitan dengan Delapan SNP.

Berdasarkan latar belakang tersebut, ada tiga rumusan masalah dalam tulisan ini, yakni sebagai berikut.

(1) Bagaimana proses pembuatan aplikasi AWAS BANG untuk meningkatkan efisiensi kepengawasan pada sekolah binaan di Kabupaten Bangkalan?

(2) Bagaimana wujud aplikasi AWAS BANG untuk meningkatkan efisiensi kepengawasan pada sekolah binaan di Kabupaten Bangkalan?

(3) Bagaimana respons pengawas terhadap aplikasi AWAS BANG untuk meningkatkan efisiensi kepengawasan pada sekolah binaan di Kabupaten Bangkalan? 
Yustinus Budi Setyanta

Pembuatan Aplikasi “Awas Bang” untuk Meningkatkan Efisiensi Kepengawasan pada Sekolah Binaan di Kabupaten Bangkalan

Berdasarkan rumusan masalah tersebut, tujuan pembuatan aplikasi ini adalah sebagai berikut:

(1) mendeskripsikan proses pembuatan aplikasi AWAS BANG untuk meningkatkan efisiensi kepengawasan pada sekolah binaan di Kabupaten Bangkalan;

(2) mendeskripsikan wujud aplikasi AWAS BANG untuk meningkatkan efisiensi kepengawasan pada sekolah binaan di Kabupaten Bangkalan;

(3) mendeskripsikan respons pengawas terhadap aplikasi AWAS BANG untuk meningkatkan efisiensi kepengawasan pada sekolah binaan di Kabupaten Bangkalan.

\section{KAJIAN PUSTAKA}

Dalam Undang-Undang Nomor 20 Tahun 2003, tentang Sistem Pendidikan Nasional (http://luk.staff.ugm. ac.id) dan Permendiknas Nomor 12 Tahun 2007 (https://luk.staff.ugm.ac.id) tentang Standar Pengawas Sekolah/Madrasah disebutkan enam dimensi kompetensi pengawas sekolah, yakni kompetensi kepribadian, supervisi manajerial, supervisi akademik, evaluasi pendidikan, penelitian dan pengembangan, serta kompetensi sosial.

Sementara itu, dalam Permenpan dan RB No. 21 Tahun 2010, tentang Jabatan Fungsional Pengawas dan Angka Kreditnya, dinyatakan bahwa pengawas sekolah adalah jabatan fungsional yang memiliki tugas, tanggung jawab, dan wewenang untuk melaksanakan kegiatan supervisi akademik dan manajerial pada satuan pendidikan yang menjadi binaannya. Oleh sebab itu, kegiatan tersebut harus direncanakan dan diorganisasikan dengan baik, kemudian dilaksanakan secara sungguh-sungguh sesuai paradigma pendidikan yang bertumpu pada empat pilar pendidikan: pendidikan untuk semua, demokratis, bertumpu pada kebudayaan lokal, dan seimbang antara imtaq dan iptek. Keempat hal tersebut dapat terwujud jika semua stakeholder turut terlibat aktif di dalamnya. Salah satu hal yang dapat dilakukan pengawas sekolah adalah melalui supervisi (https:// bkpsdm.agamkab.go.id/).

Permenpan dan RB No. 21 Tahun 2010 tersebut kemudian ditindaklanjuti dengan diterbitkannya peraturan bersama antara Mendiknas dan Kepala BKN No. 01/III/PB/2011 tentang Petunjuk Pelaksanaan Jabatan Fungsional Pengawas Sekolah dan Angka Kreditnya (https://www.bkn.go.id/) serta Permendikbud Republik Indonesia No. 143 Tahun 2014 tentang 
Yustinus Budi Setyanta

Pembuatan Aplikasi “Awas Bang” untuk Meningkatkan Efisiensi Kepengawasan pada Sekolah Binaan di Kabupaten Bangkalan

Petunjuk Teknis Jabatan Fungsional Pengawas Sekolah dan Angka Kreditnya (https://jdih. kemdikbud.go.id/).

Regulasi jabatan pengawas tersebut saat ini telah direvisi dengan dikeluarkannya Permeneg PAN dan RB Nomor 14 Tahun 2016 tentang jabatan pengawas dan angka kreditnya (https://jdih.menpan.go.id/). Dalam peraturan tersebut, dinyatakan bahwa jabatan fungsional pengawas sekolah adalah jabatan fungsional yang memiliki ruang lingkup tugas, tanggung jawab, dan wewenang untuk melaksanakan kegiatan supervisi akademik dan manajerial pada satuan pendidikan. Peraturan tersebut kemudian ditindaklanjuti dengan diterbitkannya Surat Edaran antara Kemendikbud dan Kepala BKN No. 01/Tahun 2016 dan No. 01/SE/XII/2016 pada 13 Desember 2016 (https://www.berkasedukasi.com).

Dalam regulasi tersebut, ada empat kegiatan pokok kepengawasan: (1) menyusun program pengawasan, (2) melaksanakan program pengawasan, (3) evaluasi hasil pelaksanaan program, dan (4) melaksanakan pembimbingan dan pelatihan profesional guru. Untuk itu, pengawas sekolah perlu melakukan supervisi, baik supervisi akademik maupun manajerial.

Tugas-tugas pokok tersebut, khususnya yang berkaitan dengan pelaksanaan program dan evaluasi atas hasil pelaksanaan program dapat berjalan efektif dan efisien jika didukung instrumen yang dapat membantu mempermudah dalam penjaringan data supervisi. Instrumen yang dimaksud berupa aplikasi berbasis teknologi dengan menggunakan VBA (Visual Basic for Application).

VBA adalah fungsi Visual Basic yang tertanam dalam peranti lunak, yakni alat untuk mengembangkan program pengontrolan Excel (https://id.wikipedia.org). Program Excel banyak digunakan sebagai alat penyelesaian tugas secara berulang dan terus menerus. Ada beberapa kegunaan Microsoft Excel yang sering dijumpai, di antaranya adalah untuk (1) mengelola data nilai, mengelola data penggajian, serta mengelola agenda kegiatan, (2) mengelola transaksi, menghasilkan faktur, dan mencetak kuitansi transaksi, dan (3) mengelola perkembangan grafik atas data yang disimpan dalam dimensi data pada Excel. Selain itu, ada kegunaan lain yang juga sangat penting, yakni melakukan otomatisasi beberapa fungsi Excel agar lebih mudah, sederhana, dan singkat. VBA pada macro Excel menjadi penunjang untuk melakukan beberapa hal tersebut. 
Yustinus Budi Setyanta

Pembuatan Aplikasi “Awas Bang” untuk Meningkatkan Efisiensi Kepengawasan pada Sekolah Binaan di Kabupaten Bangkalan

Terdapat beberapa deskripsi fungsi VBA dalam macro Excel (https://www. broexcel.com), yakni sebagai berikut. Pertama, dapat melakukan pengetikan untuk memasukkan beberapa data ke dalam worksheet (lembar kerja) secara sekaligus. Hal itu lebih condong pada penggunaan Excel untuk mencatat data yang dilakukan secara rutin. Sebagai contoh, data nama dan nilai yang diperoleh siswa, kemudian data nilai tersebut ditempatkan pada lembar worksheet yang berbeda. Kedua, pekerjaan yang dilakukan secara rutin, seperti membuat laporan pemasukan dan pengeluaran kas setiap hari. Untuk tujuan tersebut, macro Excel mampu melakukannya dengan mudah. Otomasi tanggal dapat diatur sehingga laporan tercatat tepat waktu. Ketiga, jika terdapat tindakan yang dilakukan bersama, misalnya mengerjakan tugas yang membutuhkan tiga workbook Excel berbeda, VBA dapat merekam makro saat melakukan pekerjaan pada workbook pertama, kemudian membiarkan makro mengulangi tindakan pada workbook lainnya. Keempat, VBA memiliki fitur untuk melakukan otomatisasi perintah menjadi satu. Sebagai contoh, dalam satu tombol akan dilakukan perintah otomatis untuk melakukan beberapa fungsi sekaligus, misalnya perintah kalkulasi sekaligus perintah cetak. Kelima, dengan menggunakan VBA seluruh layout yang ditampilkan pada worksheet dapat diatur sehingga pekerjaan akan lebih fokus. Hal yang demikian tentu saja akan membantu rekan kerja yang tidak memiliki pemahaman yang baik tentang komputer. Keenam, pada Excel tersedia banyak formula matematis. Akan tetapi, dengan fitur VBA hal itu akan lebih mudah dilakukan.

\section{METODE PENELITIAN}

Penelitian ini menggunakan desain Research and Development $(R \& D)$, yakni penelitian untuk menghasilkan produk tertentu, kemudian menguji keefektifan produk tersebut (Sugiyono, 2012:172). Sementara itu, menurut Borg and Gall, penenelitian dan pengembangan merupakan strategi tepat untuk meningkatkan praktik (http://ejournal.radenintan.ac.id).

Berkaitan dengan hal tersebut, produk yang dihasilkan dalam penelitian dan pengembangan mengandung empat pengertian pokok, yakni (1) produk tidak hanya meliputi perangkat keras, tetapi juga perangkat lunak yang berupa aplikasi, (2) merupakan produk baru atau hasil modifikasi produk sebelumnya, (3) produk memiliki kebermanfaatan, dan (4) dapat dipertanggungjawabkan, baik secara praktis maupun keilmuan (Arifin, 2012: 127). 
Pembuatan Aplikasi “Awas Bang” untuk Meningkatkan Efisiensi Kepengawasan pada Sekolah Binaan di Kabupaten Bangkalan

Dalam rangka pengembangan produk AWAS BANG, model yang digunakan adalah versi Borg dan Gall (dalam Emzir, 2011: 275) yang dimodifikasi ke dalam lima langkah: (1) pengumpulan informasi, (2) perencanaan, (3) pengembangan desain produk, (4) uji lapangan, dan (5) revisi produk.

Pada tahap pengumpulan informasi dilakukan penentuan tagihan supervisi. Hal itu disesuaikan dengan Program Tahunan dan Program Semester Kepengawasan. Langkah yang dilakukan berupa studi pustaka dengan mengumpulkan teori-teori yang berkaitan dengan program kepengawasan sehingga didapatkan gambaran umum tentang produk yang akan dibuat atau dikembangkan. Sementara itu, studi lapangan dilakukan dengan mengkaji instrumen supervisi yang dimiliki pengawas saat melakukan kunjungan ke sekolah binaan. Berdasarkan langkah tersebut diperoleh informasi bahwa instrumen supervisi yang digunakan masih berupa pemberian skor pada lembar-lembar kertas; belum mengeksplorasi kemajuan teknologi.

Pada tahap perencanaan dilakukan kajian terhadap aspek-aspek yang akan disusun dalam aplikasi kepengawasan, menentukan skor tiap aspek dengan menggunakan skala likert (4-3-2-1-0). Pada tahap pengembangan desain produk dilakukan kegiatan pengumpulan referensi dan perancangan produk aplikasi. Pada tahap uji lapangan dan revisi produk akhir dilakukan validasi oleh pengawas senior tentang aspek-aspek yang disupervisi dan ahli aplikasi berbasis VBA yang berkaitan dengan kelayakan program aplikasi. Revisi akan dilakukan berdasarkan masukan pengawas senior dan ahli aplikasi.

Instrumen yang digunakan dalam pengumpulan data respons pengawas pada penelitian ini berupa kuesioner (angket). Angket tersebut digunakan untuk memperoleh data tentang respons pengawas terhadap aplikasi AWAS BANG yang dibuat. Ada sepuluh pertanyaan dalam angket tersebut dengan dua pilihan jawaban, yakni "Ya" dan "tidak". Data yang telah terkumpul, kemudian dianalisis untuk mengetahui kualitas produk yang dihasilkan, yakni dari segi instrumen supervisi dan tampilan produk aplikasi kepengawasan yang akan digunakan.

Analisis data yang digunakan dalam penelitian ini adalah analisis deskriptif, dengan langkah-langkah sebagai berikut: 
Pembuatan Aplikasi “Awas Bang” untuk Meningkatkan Efisiensi Kepengawasan pada Sekolah Binaan di Kabupaten Bangkalan

(1) Pengumpulan data melalui angket dari seluruh pengawas Cabang Dinas Wilayah Kabupaten Bangkalan.

(2) Pembuatan tabulasi data yang diperoleh melalui angket.

(3) Menghitung persentase setiap angket dengan rumus:

Persentase $=\quad \begin{gathered}\text { Jumlah Jawaban "Ya/Tidak" } \\ \text { - Jumlah Pertanyaan }\end{gathered}$

(4) Membuat rekapitulasi data berdasarkan hasil angket.

Selain itu, dilakukan pula wawancara dengan pengawas senior berkaitan dengan kesesuaian data instrumen supervisi yang terdapat dalam aplikasi dan validasi ahli aplikasi yang berkaitan dengan tampilan dan kelayakan aplikasi. Berdasarkan hasil angket dan wawancara tersebut, dilakukan uji coba kepada para pengawas saat melakukan supervisi ke sekolah binaan.

\section{HASIL PENELITIAN DAN PEMBAHASAN}

Penelitian pengembangan untuk meningkatkan efisiensi kepengawasan dilakukan melalui berbagai tahap kegiatan, mulai dari pengumpulan informasi, perancangan/desain aplikasi, pembuatan aplikasi, dan pengujian produk. Tahapan tersebut secara urut dipaparkan pada bagian berikut ini.

Pada tahap pengumpulan informasi dilakukan pemetaan tagihan supervisi yang akan dilakukan pada tiap bulannya. Hal itu disesuaikan dengan Program Kerja Pengawas Sekolah, baik Program Tahunan dan Program Semester. Langkah yang dilakukan berupa studi pustaka dengan mengumpulkan teori-teori yang berkaitan dengan program kepengawasan untuk mendapatkan gambaran umum mengenai produk yang akan dikembangkan. Hal yang tidak kalah pentingnya adalah dengan mencermati tugas pokok pengawas sekolah, baik di bidang pengawasan akademik maupun manajerial.

Sementara itu, studi lapangan dilakukan untuk mengkaji instrumen yang dibawa pengawas saat melakukan supervisi ke sekolah binaan. Berdasarkan langkah tersebut diperoleh informasi bahwa pelaksanaan supervisi dan instrumen yang digunakan masih dilakukan secara manual (memberikan nilai pada lembar-lembar kertas) belum mengeksplorasi kemajuan teknologi. 
Yustinus Budi Setyanta

Pembuatan Aplikasi “Awas Bang” untuk Meningkatkan Efisiensi Kepengawasan pada Sekolah Binaan di Kabupaten Bangkalan

Dari kedua hal tersebut, diperoleh data berupa aspek-aspek yang akan disupervisi oleh pengawas. Langkah selanjutnya adalah melakukan pemetaan tagihan supervisi untuk masing-masing bulan. Untuk itu, perhatikan tabel 1 tentang pemetaan supervisi berikut ini!

Tabel 1. Pemetaan Aspek Supervisi (Per Bulan)

\begin{tabular}{|c|c|c|c|}
\hline No & Semester & Bulan & Aspek Yang Disupervisi \\
\hline $\mathbf{1}$ & Gasal & Juli & $\begin{array}{l}\text { - Pelaksanaan Evaluasi (Sem. Genap) } \\
\text { - Administrasi Kurikulum Dan Pembelajaran } \\
\text { - Persiapan Dan Kegiatan Awal Tahun Pelajaran } \\
\text { - Monitoring Masa Pengenalan Lingkungan Sekolah } \\
\text { (MPLS) } \\
\text { - Monitoring PPDB }\end{array}$ \\
\hline 2 & & Agustus & $\begin{array}{l}\text { - Administrasi Dan Manajemen } \\
\text { - Kelembagaan, Ketenagaan, Dan Pembiayaan }\end{array}$ \\
\hline 3 & & September & $\begin{array}{l}\text { - Sarana Dan Prasarana } \\
\text { - Administrasi Urusan Kurikulum }\end{array}$ \\
\hline 4 & & Oktober & - Manajemen Kepala Sekolah \\
\hline 5 & & November & - Administrasi Sekolah (Ketatausahaan) \\
\hline 6 & Genap & $\begin{array}{c}\text { Desember } \\
\text { Januari }\end{array}$ & $\begin{array}{l}\text { - Administrasi Kesiswaan (Peserta Didik) } \\
\text { - Pelaksanaan Evaluasi (Sem. Gasal) } \\
\text { - Sumber Daya Sekolah }\end{array}$ \\
\hline 8 & & Februari & - Perpustakaan \\
\hline 9 & & Maret & $\begin{array}{l}\text { - Kegiatan Bimbingan Dan Konseling } \\
\text { - Muatan Lokal }\end{array}$ \\
\hline 10 & & April & $\begin{array}{l}\text { - Laboratorium } \\
\text { - Pengembangan Diri (Ekstrakurikuler) }\end{array}$ \\
\hline 11 & & Mei & $\begin{array}{l}\text { - Lingkungan Budaya Sekolah, Serta Peran Serta } \\
\text { Masyarakat } \\
\text { - Koperasi Sekolah }\end{array}$ \\
\hline 12 & & Juni & $\begin{array}{l}\text {-Pelaksanaan Pembelajaran } \\
\text { - } 7 \mathrm{~K}\end{array}$ \\
\hline
\end{tabular}

Pada tahap proses pembuatan aplikasi AWAS BANG dilakukan dengan langkahlangkah sebagai berikut.

1) Membuat halaman depan aplikasi yang di dalamnya berisi nama program dan namanama bulan, seperti tampak pada gambar 1 berikut ini.

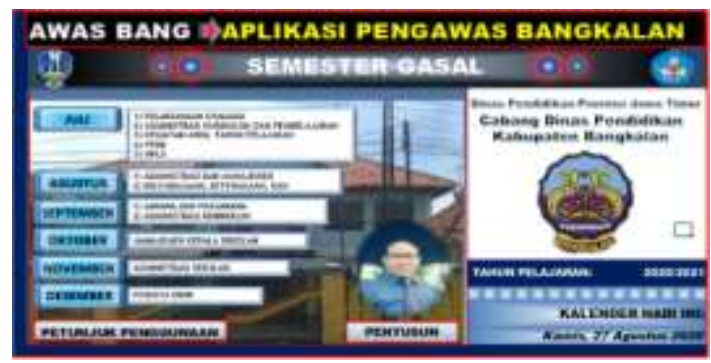

Gambar 1. Halaman Depan Aplikasi Tiap Semester 
Pembuatan Aplikasi “Awas Bang” untuk Meningkatkan Efisiensi Kepengawasan pada Sekolah Binaan di Kabupaten Bangkalan

2) Membuat halaman depan program untuk masing-masing bulan, seperti tampak pada gambar 2 berikut ini.

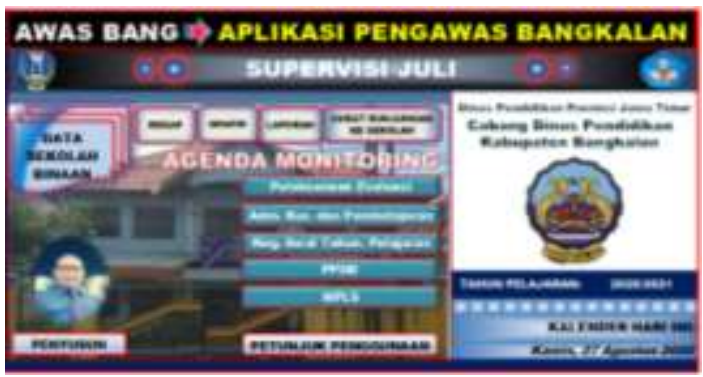

Gambar 2. Halaman Depan Aplikasi Per Bulan

3) Membuat format database dan melengkapinya dengan data-data sekolah binaan dan identitas pengawas, seperti tampak pada gambar 3 berikut ini.

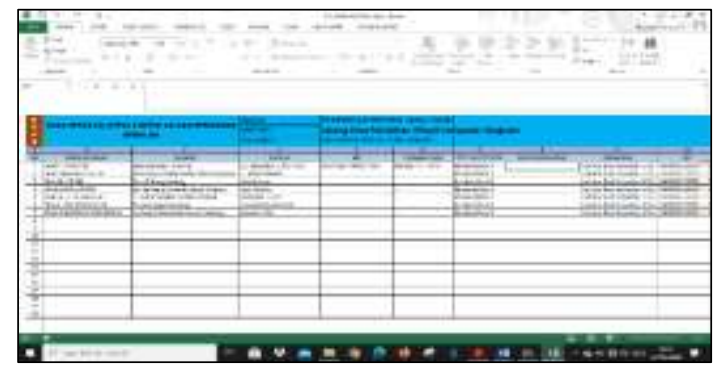

Gambar 3. Database (Data Awal)

4) Membuat instrumen monitoring yang disesuaikan dengan pemetaan aspek supervisi pada tiap bulannya, kemudian memasukkan berbagai rumus tertentu agar dapat selaras dengan database yang telah dibuat sebelumnya. Selain itu, dimasukkan pula rumus tertentu untuk mengukur skor tiap aspek dengan cara memberikan /mengetikkan huruf $\mathrm{V}$ pada sel/kolom yang sesuai dengan penilaian yang diberikan pengawas $(4,3,2,1,0)$. Secara otomatis, huruf $\mathrm{V}$ yang diketik tersebut berubah menjadi angka pada sel/kolom skor. Jika semua aspek telah diberikan tanda huruf $\mathrm{V}$, dapat diketahui skor akhirnya dengan kategori Sangat Baik, Baik, Cukup, Sedang, atau Kurang, seperti tampak pada gambar 4 berikut.
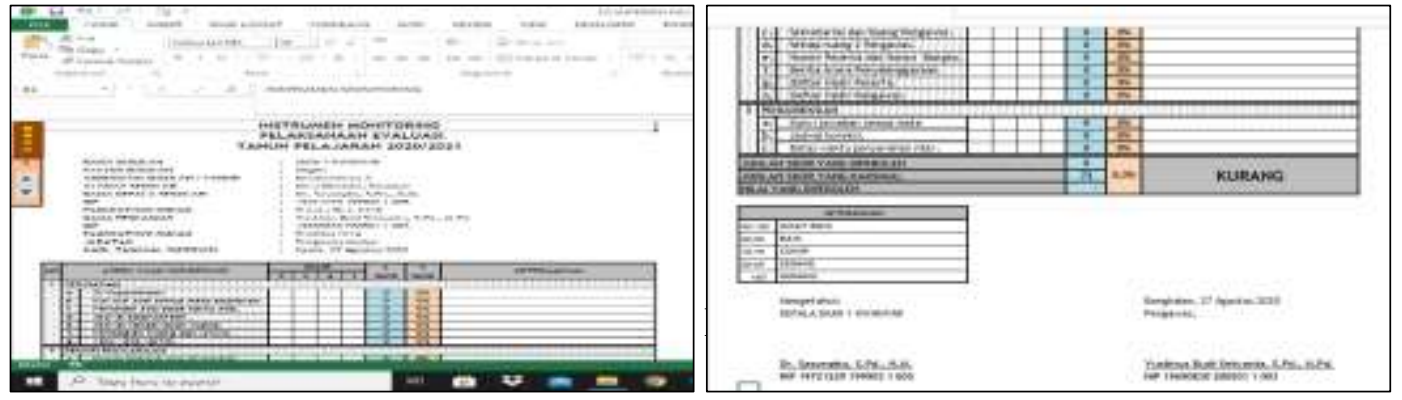
Yustinus Budi Setyanta

Pembuatan Aplikasi “Awas Bang” untuk Meningkatkan Efisiensi Kepengawasan pada Sekolah Binaan di Kabupaten Bangkalan

Untuk beralih ke sekolah binaan lain dibuatkan pula tombol panah naik-turun (UpDown), seperti tampak gambar 4. Dengan meng-klik tombol naik atau turun nama sekolah akan berubah. Jika nama sekolah berubah, semua identitas yang berkaitan dengan sekolah tersebut secara otomatis berubah.

1) Pada sheet rekapitulasi hasil supervisi dan grafik skor selama satu bulan akan secara otomatis terisi sesuai dengan pemberian skor sebelumnya (pada sheet instrumen monitoring). Identitas sekolah dan nama pengawas akan mengacu pada halaman awal saat kita memberikan penilaian/skoring. Begitu pula pada sheet laporan dan surat kunjungan ke sekolah, seperti tampak pada gambar 5 berikut ini.
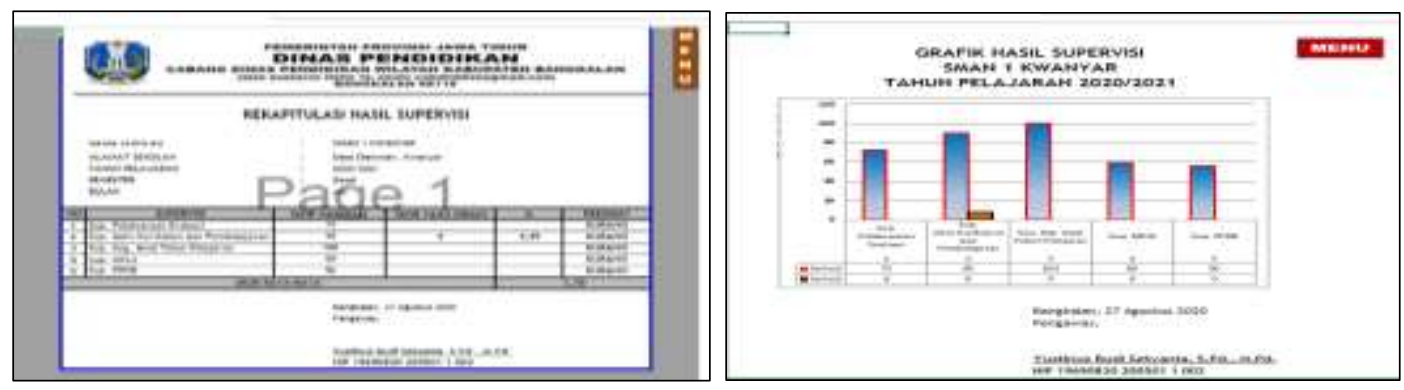

Gambar 5. Hasil Rekapitulasi dan Grafik

Pembuatan aplikasi kepengawasan berbasis VBA Excel ternyata mendapatkan respons positif dari para pengawas, khususnya pengawas di lingkungan Cabang Dinas Pendidikan Wilayah Kabupaten Bangkalan yang berjumlah lima belas orang. Hal itu tampak dari angket yang diisi oleh pengawas yang hasilnya tampak pada tabel rekapitulasi berikut ini.

Tabel 2. Rekapitulasi Angket Respons Pengawas terhadap Aplikasi AWAS BANG

\begin{tabular}{|c|c|c|c|c|c|}
\hline \multirow{2}{*}{ No } & \multirow{2}{*}{ Pertanyaan } & \multicolumn{2}{|c|}{$\sum$ Jawaban } & \multicolumn{2}{|c|}{ \% Jawaban } \\
\hline & & Ya & Tidak & Ya & Tidak \\
\hline 1 & $\begin{array}{l}\text { Apakah selama Anda menjadi pengawas } \\
\text { sekolah pernah menggunakan aplikasi } \\
\text { kepengawasan? }\end{array}$ & 3 & 12 & $20,00 \%$ & $80,00 \%$ \\
\hline 2 & $\begin{array}{l}\text { Apakah ada keinginan sebelumnya untuk } \\
\text { menggunakan aplikasi kepengawasan? }\end{array}$ & 10 & 5 & $66,67 \%$ & $33,33 \%$ \\
\hline 3 & $\begin{array}{l}\text { Apakah Anda terbantu dengan aplikasi } \\
\text { AWAS BANG? }\end{array}$ & 15 & 0 & $100,00 \%$ & $0,00 \%$ \\
\hline 4 & $\begin{array}{l}\text { Apakah aplikasi AWAS BANG membuat } \\
\text { tugas Anda menjadi lebih efisien? }\end{array}$ & 15 & 0 & $100,00 \%$ & $0,00 \%$ \\
\hline & 11 & & & & \\
\hline
\end{tabular}




\begin{tabular}{|c|c|c|c|c|c|}
\hline \multirow{2}{*}{ No } & \multirow{2}{*}{ Pertanyaan } & \multicolumn{2}{|c|}{$\sum$ Jawaban } & \multicolumn{2}{|c|}{ \% Jawaban } \\
\hline & & $\mathbf{Y a}$ & Tidak & Ya & Tidak \\
\hline & Apakah aplikasi AWAS BANG & & & & \\
\hline 5 & $\begin{array}{l}\text { mempermudah komunikasi antara pengawas } \\
\text { dan sekolah binaan? }\end{array}$ & 12 & 3 & $80,00 \%$ & $20,00 \%$ \\
\hline 6 & $\begin{array}{l}\text { Apakah aplikasi AWAS BANG perlu } \\
\text { dikembangkan pada aspek supervisi yang } \\
\text { lain? }\end{array}$ & 15 & 0 & $100,00 \%$ & $0,00 \%$ \\
\hline 7 & $\begin{array}{l}\text { Apakah Anda mengalami kesulitan dalam } \\
\text { pengoperasian aplikasi AWAS BANG? }\end{array}$ & 1 & 14 & $6,67 \%$ & $93,33 \%$ \\
\hline 8 & $\begin{array}{l}\text { Apakah di sekolah binaan Anda } \\
\text { memberikan sambutan yang baik terhadap } \\
\text { penggunaan aplikasi AWAS BANG dalam } \\
\text { supervisi? }\end{array}$ & 15 & 0 & $100,00 \%$ & $0,00 \%$ \\
\hline 9 & $\begin{array}{l}\text { Apakah Anda akan selalu menggunakan } \\
\text { aplikasi AWAS BANG pada setiap supervisi } \\
\text { di sekolah binaan? }\end{array}$ & 10 & 5 & $66,67 \%$ & $33,33 \%$ \\
\hline 10 & $\begin{array}{l}\text { Apakah Anda akan mendiseminasikan } \\
\text { aplikasi AWAS BANG kepada pengawas di } \\
\text { daerah lain? }\end{array}$ & 8 & 7 & $53,33 \%$ & $46,67 \%$ \\
\hline
\end{tabular}

Jika tabel 1 tersebut dibuat dalam bentuk grafik, akan tampak, seperti grafik 1 yang berikut ini.

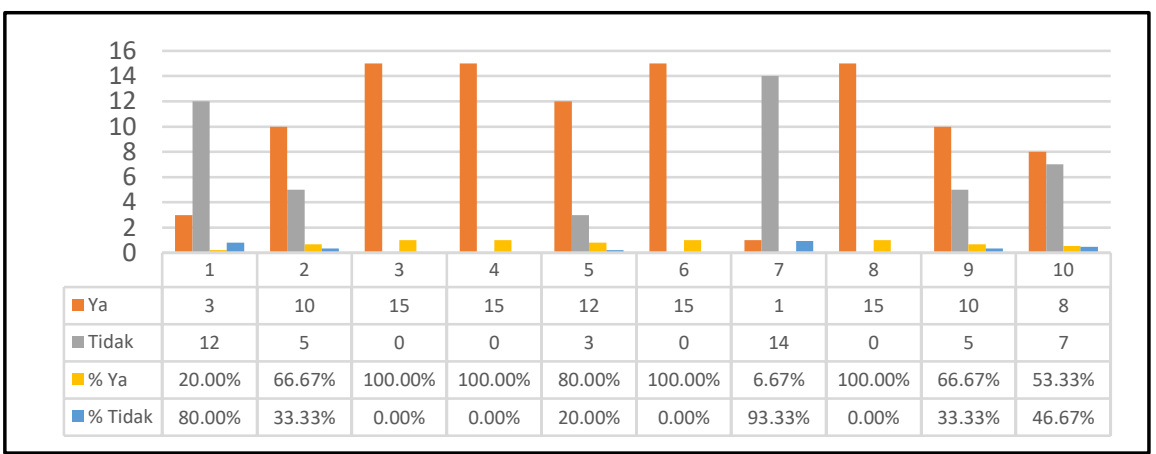

Grafik 1. Rekapitulasi Angket Respons Pengawas terhadap Aplikasi AWAS BANG

Dari tabel 2 dan grafik 1, terindikasikan bahwa dari 15 pengawas sekolah yang ada di Cabang Dinas Pendidikan Wilayah Kabupaten Bangkalan, hanya ada 3 pengawas sekolah (20\%) yang sebelumnya pernah menggunakan aplikasi kepengawasan, sementara sisanya, 12 pengawas (80\%) belum pernah menggunakannya dan ada 10 pengawas $(66,67 \%)$ yang menyatakan bahwa sebelumnya ingin menggunakan aplikasi kepengawasan. Dari tabel tersebut juga tampak bahwa semua pengawas (100\%) terbantu dengan aplikasi AWAS BANG karena membuat tugas kepengawasan menjadi lebih efisien serta berharap aplikasi ini dikembangkan pada aspek supervisi yang lain karena sekolah binaan memberikan sambutan 
Pembuatan Aplikasi “Awas Bang” Untuk Meningkatkan Efisiensi Kepengawasan Pada Sekolah Binaan Di Kabupaten Bangkalan

yang baik terhadap penggunaan aplikasi AWAS BANG oleh pengawas dalam supervisi. Selain itu, ada 12 pengawas (80\%) yang menyatakan bahwa aplikasi ini mempermudah komunikasi antara pengawas dan sekolah binaan. Oleh sebab itu, sebagian besar pengawas $(66,67 \%)$ selalu menggunakan aplikasi ini pada setiap supervisi di sekolah binaan. Oleh sebab itulah, mereka akan mendiseminasikan aplikasi AWAS BANG kepada pengawas di daerah lain karena terbukti aplikasi tersebut mudah dioperasikan.

Dari hasil wawancara dengan pengawas senior diperoleh masukan bahwa semua bentuk supervisi harus mengacu pada program kepengawasaan, baik program tahunan, maupun program semester. Program-program tersebut dilaksanakan pada bulan tertentu. Sementara itu, dari hasil wawancara dengan ahli aplikasi diperoleh masukan bahwa aplikasi AWAS BANG sudah cukup representatif dan layak untuk digunakan sebagai sarana supervisi oleh pengawas.

Pada tahap akhir dilakukan uji coba aplikasi dengan mengundang seluruh pengawas di lingkungan Cabang Dinas Pendidikan Wilayah Kabupaten Bangkalan. Selanjutnya, pada minggu berikutnya juga mengundang seluruh kepala sekolah dan waka kurikulum, baik SMA negeri maupun swasta. Pada kesempatan tersebut, penulis memaparkan cara kerja AWAS BANG. Dari pertanyaan dan tanggapan para pengawas dan kepala sekolah, tampak bahwa seluruh peserta yang hadir memberikan apresiasi atas inovasi dalam bidang kepengawasan ini. Bukti kegiatan tersebut dapat dilihat pada foto-foto berikut ini.
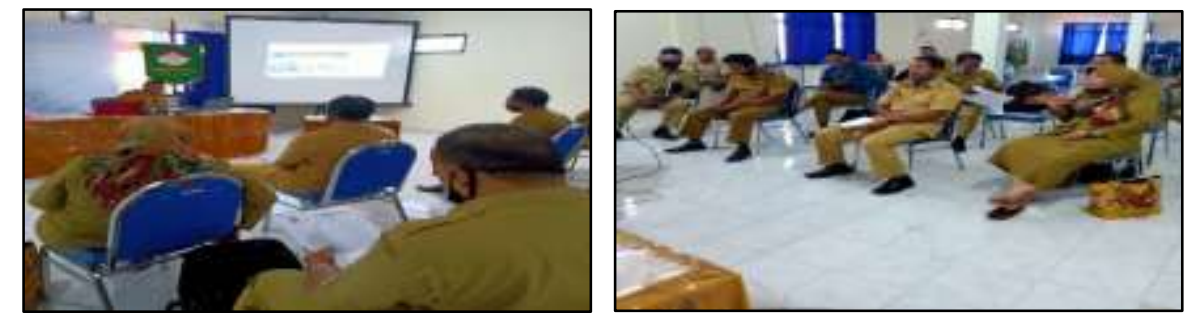

Foto 1. Pemaparan Aplikasi kepada Seluruh Pengawas Cabang Dinas Kabupaten Bangkalan
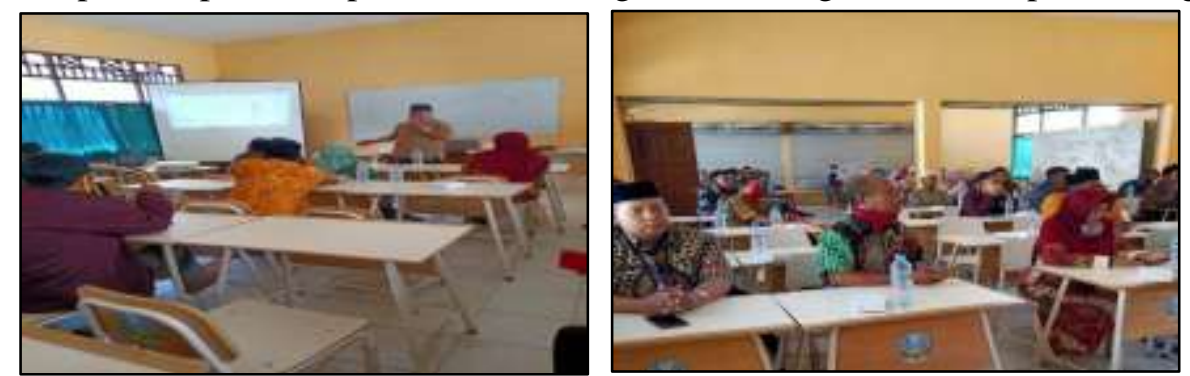

Foto 2. Pemaparan Aplikasi kepada Para Kepala Sekolah dan Waka Kurikulum se-Kabupaten Bangkalan 
Yustinus Budi Setyanta

Pembuatan Aplikasi “Awas Bang” Untuk Meningkatkan Efisiensi Kepengawasan Pada Sekolah Binaan Di Kabupaten Bangkalan

\section{SIMPULAN DAN SARAN}

Pengawas sekolah memiliki peran penting dalam pengembangan kualitas pendidikan di sekolah yang menjadi binaannya. Akan tetapi, selama ini, sepanjang pengetahuan penulis, tidak ada aplikasi kepengawasan per bulan sesuai dengan program kerja pengawas, baik program tahunan maupun semester. Hal tersebut menjadi keprihatinan penulis, terutama di saat pandemi covid-19 yang berimbas pada semua aspek kehidupan, termasuk di bidang pendidikan.

Berangkat dari kenyataan tersebut, AWAS BANG (Aplikasi Pengawas Bangkalan) adalah sebuah jawaban atas hal yang demikian. Aplikasi tersebut dibangun dengan menggunakan VBA (Visual Basic for Application) yang bekerja pada macro excel.

Dengan AWAS BANG, tugas kepengawasan menjadi lebih efisien karena pengawas tinggal mengetikkan huruf "V" pada sel/kolom yang sesuai dengan instrumen supervisi pada tiap aspeknya. Skor dan kategori supervisi pada sel penilaian secara otomatis akan terhubung ke sel skor akhir dan rekapitulasi hasil. Dengan demikian, pengawas tidak perlu menghitung lagi skor yang diperoleh pada tiap indikator. Terlebih lagi tersedia pula grafik, laporan hasil supervisi, dan surat kunjungan ke sekolah binaan. Semua itu sudah terisi jika sebelumnya pengawas mengetikkan identitas sekolah dan pengawas pada database.

Pembuatan aplikasi AWAS BANG terbukti mampu meningkatkan kinerja kepengawasan menjadi semakin efisien karena pengawas dapat mengirimkan aplikasi terlebih dahulu, kemudian sekolah binaan diminta mengisinya. Hal yang demikian tentu perlu dilakukan jika akses menuju sekolah binaan relatif sulit dijangkau. Pada suatu kesempatan pengawas sekolah dapat langsung memberikan validasi saat mengadakan kunjungan di sekolah binaan.

Oleh sebab itu, ada beberapa saran yang dapat dikemukakan pada bagian ini, di antaranya adalah sebagai berikut. Pertama, aplikasi AWAS BANG adalah aplikasi sederhana yang dibuat oleh penulis yang tidak mempelajari teknologi informasi dan komunikasi secara formal. Oleh sebab itu, aplikasi ini masih cukup luas untuk dapat dikembangkan agar menjadi lebih sempurna. Kedua, aplikasi ini seyogianya dapat dimanfaatkan oleh para pengawas dari wilayah kabupaten/kota atau provinsi lain karena telah terbukti tidak sulit dalam pengoperasiannya dan sangat membantu efisiensi kinerja kepengawasan.

\section{DAFTAR PUSTAKA}


Pembuatan Aplikasi “Awas Bang” Untuk Meningkatkan Efisiensi Kepengawasan Pada Sekolah Binaan Di Kabupaten Bangkalan

Arifin, Z. (2012). Model Penelitian dan Pengembangan. Bandung: PT Remaja Rosdakarya.

Emzir. (2011). Metodologi Penelitian Kualitatif Analisis Data. Jakarta: PT Raja Grafindo Persada Pusat.

https://id.wikipedia. org/ wiki/Visual_Basic_for_Applications. Diakses pada 27 Agustus 2020.

https://www. broexcel.com/pengertian-dan-fungsi-dari-macro-vba.html. Diakses pada 27 Agustus 2020.

http://ejournal.radenintan.ac.id. Diakses pada 26 Agustus 2020.

Peraturan Bersama antara Mendiknas dan Kepala BKN Nomor 01/III/PB/2011. Tersedia https://www.bkn.go.id/ Diakses pada 26 Agustus 2020.

Permen PAN dan RB Nomor 21 Tahun 2010. Tersedia https://bkpsdm.agamkab.go.id/?p=2547. Diakses pada 27 Agustus 2020.

Permendiknas Nomor 12 Tahun 2007 tentang Standar Pengawas Sekolah/Madrasah. Tersedia https://luk.staff.ugm.ac.id. Diakses pada 26 Agustus 2020.

Peraturan Menteri Pendidikan dan Kebudayaan Republik Indonesia Nomor 143 Tahun 2014. Diakses dari https://jdih.kemdikbud.go.id/arsip. Diakses pada 26 Agustus 2020.

Permeneg PAN dan RB Nomor 14 Tahun 2016. Tersedia https://jdih.menpan.go.id/_Diakses pada 27 Agustus 2020.

Sugiyono. (2012). Metode Penelitian Bisnis. Bandung: Alfabeta.

Surat Edaran antara Kemendikbud dan Kepala BKN Nomor 01/Tahun 2016 dan No. 01/SE/XII/2016. Diakses dari https://www.berkasedukasi.com.

Undang-Undang Nomor 20 Tahun 2003, tentang Sistem Pendidikan Nasional. Tersedia http://luk.staff.ugm.ac.id/atur/UU20-2003.Sisdiknas.pdf. Diakses pada 26 Agustus 2020. 